\title{
DIAGNÓSTICO DA IMPLANTAÇÃO DOS NOVOS CURRÍCULOS DE LÍNGUA INGLESA NAS ESCOLAS ESTADUAIS DE LONDRINA-PARANÁ
}

\author{
CORINA MARIA TEDESCHI BUSNARDO 1 \\ MARIA REGINA FILGUEIRA DOS REIS ${ }^{2}$
}

BUSNARDO, C.M.; REIS, M.R.F. Diagnóstico da Implantação dos Novos Currículos de Língua Inglesa nas Escolas
Estaduais de Londrina, PR. Semina: Ci. Soc./Hum., Londrina, v. 15, n. 3, p. 205-214, set. 1994.

RESUMO: O objetivo deste trabalho é diagnosticar, através de entrevistas individuais, se e como vem ocorrendo a implanta. ção dos novos currículos de Lingua Inglesa para o $7^{\circ}$ e $2^{\circ}$ graus, em 10 escolas estaduais da cidade de Londrina, Paraná. Participaram da pesquisa 29 professores e 10 coordenadores/supervisores na $1^{a}$ fase da coleta dos dados, 24 professores e 15 coordenadores/supervisores na $2^{a}$ fase. Os dados demonstram que, devido a falhas no processo de divulgação, preparação prévia e acompanhamento, os professores e coordenadores/supervisores, não vêm, na sua totalidade, implantando os novos currículos propostos pelo governo do Estado desde 1990 (1ㅇ grau) e 1988 (2ㅇ grau). Este trabalho tenta também detectar os problemas causados por uma implantação assistemática e sugerir mecanismos para minimizar as conseqüencias para o ensino da Lingua Inglesa nas escolas estaduais de Londrina.

PALAVRAS-CHAVE: Currículo - Lingua Inglesa, Ensino $1^{\circ}$ e $2^{\circ}$ graus, Lingua Inglesa; Professor-desenvolvimento, Curriculo Implantação

\section{1 - INTRODUÇÃO}

Na tentativa de reverter a situação diflcil do ensino em geral no Estado do Paranå, a Secretaria de Estado de Educação (SEED) lançou propostas de reestruturação dos currículos de $1^{\circ}$ e $2^{\circ}$ graus, através dos documentos Curriculo Básico para a Escola Pública do Parana (1990) e Reestruturaçāo do Ensino de 2 Grau-Linguas Estrangeiras Modernas (1988).

Em Londrina, através do subprojeto de extensão à comunidade - Núcleo de Apoio Pedagógico para Profes. sores de $1^{\circ}$ e $2^{\circ}$ graus, Língua Inglesa (NAP), foram realizados em 1991, alguns "cursos-relâmpago" com o obje. tivo de verificar o resultado da implantação dos novos currículos de Lingua Inglesa. Na ocasiäo, como integrantes do referido subprojeto, constatamos, para nossa surpresa, que a grande maioria dos professores participantes daqueles cursos nem mesmo tinham conhecimento dos documentos. Além disso, confessaram que não se sentiam preparados para colocarem suas práticas educativas já solidificadas.

No ano de 1992, o NAP foi mais uma vez convidado pelo Núcleo Regional de Educação - NRE-Londrina e Centro de Treinamento do Magistério do Paraná (CETEPAR) a ministrar $40 \mathrm{~h}$. de curso de capacitação para professores de Lingua Inglesa de $1^{\circ}$ e $2^{\circ}$ graus. Esses cursos, ironicamente, visavam auxiliar os professores na implantação dos novos currículos. Percebemos, nesse momento, a falta de organização e clareza no processo de implantação dos novos curriculos por parte do governo do Paraná. Pudemos antecipar as dificuldades que esses fatores viriam acarretar. Os cursos foram ministrados, os novos curriculos foram apresentados e discutidos com os professores, e, com o acompanhamento do NAP, o processo de implantação teve início. Aqui, mais uma vez, recaiu sobre o projeto a responsabilidade de acompanhar $e$ avaliar o trabalho realizado.

Tendo em vista o que foi exposto acima, nós, docentes da UEL, participantes do projeto NAP, envolvidos com a realidade de ensino de $1^{\circ}$ e $2^{\circ}$ graus, bem como a formação de futuros profissionais de Lingua Inglesa, vimos assumir nossa parcela de contribuição no processo de implantação dos curriculos propostos pelo governo, através desta pesquisa que visa verificar se e/ou como essa implantação vem ocorrendo em algumas escolas públicas da cidade de Londrina-Paraná.

Assim sendo, este trabalho tem como objetivos:

- Gerais:

- Verificar se elou como a implantação dos novos currículos para o ensino de Língua Inglesa está sendo efetuada no $1^{\circ}$ e $2^{\circ}$ graus de 10 escolas estaduais de Londrina-Paraná.

\footnotetext{
1 - Departamento de Letras Estrangeiras Modernas, Universidade Estadual de Londrina, Caixa Postal 6001, Londrina, Paraná, Brasil, CEP 86051-970.

2 - Departamento de Letras Estrangeiras Modernas, Universidade Estadual de Londrina, Caixa Pcstal 6001, Londrina, Paraná, Brasil,
} CEP 86051-970. 
- Elaborar documento a ser enviado à SEED do Paraná e ao NRE-Londrina, divulgando os resultados da pesquisa e propondo sugestões. Londrina-Paraná.

\section{- Especlficos:}

- Diagnosticar a realidade da implantação dos novos currículos de acordo com as respostas dos entrevistados, classificando-as em três niveis:

1. Implantaçāo total, i.e., pressupostos teóricos e conteúdos estão sendo observados e seguidos;

2. Implantação parcial, i.e., conteúdos propostos estão sendo observados e seguidos, mas pressupostos teóricos não, ou vice-versa; ou ainda, outras formas de adaptações e variações possiveis estão sendo usadas;

3. Nāo Implantaçāo.

Caso a resposta dos entrevistados seja IMPLANTAÇĀO TOTAL, verificar-se-á como a implantação vem ocorrendo em relação a:

- Preparo dos professores e coordenadores (Cursos)

- Planejamento das aulas

- Confecção de materiais

- Avaliação dos resultados com base em assessoramento e acompanhamento do trabalho

Caso a resposta seja IMPLANTAÇĀO PARCIAL verificar-se-á:

- Niveis de parcialidade

- Razões de parcialidade

- Dificuldades encontradas

- Necessidades

- Sugestões

Caso a resposta seja NÄO IMPLANTAÇÃO, verificar-se-å:

- Razões para a não implantação

- Dificuldades encontradas

- Necessidades

- Sugestões

Pretendemos que os resultados desse trabalho possam fornecer à SEED e ao NRE-Londrina um diagnóstico real da implantação dos novos curriculos nas escolas, auxiliando-os na elaboração de suas futuras linhas de ação.

\section{2 - METODOLOGIA}

\section{1 - ESCOLAS ENVOLVIDAS}

Foram selecionadas 10 escolas estaduais da cicade de Londrina Paraná:

Colegio Estadual Marcelino Champagnat

Colêgio Estadual Willie Davis

Colégio Estadual Vicente Rijo

Semina Ci. Soc $/$ Hum., v. 15, n. 3, p. 205-214
Colégio Estadual José de Anchieta

Colégio Estadual Newton Guimarães

Colégio Estadual Barão do Rio Branco

Colégio Estadual Maria do Rosário Castaldi

Colégio Estadual Antonio Moraes de Barros

Colégio Estadual Dario Velloso

Colégio Estadual Gabriel Martins

\section{2 - CRITÉRIOS PARA A SELEÇÃO dAS ESCOLAS}

a. Oferta de $1^{\circ}$ e $2^{\circ}$ graus (educação geral)

b. Oferta de cursos diurnos

c. Maior número de professores

d. Facilidade de acesso

\section{3 - CRITÉRIOS PARA A SELEÇÃO DOS INFORMANTES}

Os professores e coordenadores/supervisores selecionados foram os que estavam ministrando Língua Inglesa nas escolas envolvidas e que se dispuseram a participar da pesquisa.

\section{4 - INSTRUMENTOS UTILIZADOS}

a. Entrevistas individuais com coordenadores/supervisores das escolas envolvidas;

b. Entrevistas individuais com professores de Lingua Inglesa das escolas envolvidas;

\section{3 - COLETA DOS DADOS}

A coleta dos dados da pesquisa deu-se em duas fases, 1 a fase: anterior ao $1^{\circ}$ Curso de Capacitação de professores promovido pelo CETEPAR $\left(1^{\circ}\right.$ semestre de 1992), 2- fase: posterior à realização do referido curso. Foram utilizados os mesmos instrumentos nas duas fases da coleta dos dados, porém, devido à rotatividade dos professores e coordenadores/supervisores nas escolas, nem todos os participantes foram os mesmos nas duas fases.

As entrevistas individuais foram divididas am 4 partes:

1. Da divulgação dos novos curriculos

2. Da implantação dos novos currículos

3. Das dificuldades encontradas

4. Dos resultados

Um total de 68 informantes participaram de pesqui. sas, assim distribuidos:

Iase: 29 professores e 10 coordenadores/supervisores 2. ช์ase: 24 professores e 5 coordenadores/supervisores 


\section{4 - ANÁLISE E DISCUSSÄO DOS DADOS}

4.1 - DA DIVULGAÇÃO dOS NOVOS CURRÍCULOS

\section{QUADRO DEMONSTRATIVO 1 - CONHECIMENTO DOS NOVOS CURRÍCULOS}

1. FASE

\begin{tabular}{lllllllllll}
\hline & \multicolumn{2}{c}{ SIM } & \multicolumn{2}{c}{ NÃO } & TOTAL & SIM & & NÄO & TOTAL \\
\hline & FA & F\% & FA & F\% & FA & F\% & FA & F\% & \\
\hline$P$ & 19 & 65 & 10 & 35 & 29 & 19 & 79 & 05 & 21 & 24 \\
$\mathrm{C}$ & 07 & 70 & 03 & 30 & 10 & 04 & 80 & 01 & 20 & 05 \\
\hline $\mathrm{T}$ & 26 & 67 & 13 & 33 & 39 & 23 & 79 & 06 & 21 & 19 \\
\hline
\end{tabular}

Verificamos que, apesar de nem todos os profes. sores participantes da pesquisa terem reito o curso de ca. pacitação $(40 \mathrm{~h})$ oferecido pelo governo, houve, entre $\eta^{\mathrm{g}}$ fase e a $2^{\mathrm{a}}$ fases, um aumento no percentual de profesa sores que afirmaram ter conhecimento dos documentes.

O mesmo parece ter acontecido com os coordenesdores/supervisores, embora eles não tenham sido ofi. cialmente convocados a tomar parte do curso. Poderia. mos questionar aqui esse "Eonherimeme alegado pelos informantes. Este poderia sur definido como? Lidb os documentos? Recebido? Visto? Quvido folar dos mesmos?

Dos 29 professores envolvidos na 1 a fase da coleta de dados, $10(35 \%)$ não conheciam os novos curriculos. Esse dado alterou o objetivo do nosso curso de capacitaço de 92. uma vez que o mesmo visava verificap coms implantaçäo dos curriculos vinha ocorrendo. Como fas? sendo que $35 \%$ dos professores, $30 \%$ dos coorobnadoras nem conheciam os documentos? (Quadro Demorstrativy)

Em relação às fontes disseminadoras dos novos currículos constatamos que para os 38 professores 11 coordenadores/supervisores das $1^{\text {a }}$ e $2^{\text {a }}$ fases, os cursos de capacitaçäo (92) parecem ter cumprido seu papel de divulgador dos currículos apresentados pelo governo. seguidos das escolas que aparecem como a sagunda fonte mais citada.
No Quadro Demonstrativo 2 observa-se que $84 \%$ dos professores da 19 fase, que tinham conhecimento dos documentos, consideram-nos viáveis e parcialmente viåvels Já na $2^{\text {a }}$ faso verificamos que houve uma pequena oscilaçăo, porém, nos mesmos itens $190 \%$ entre viável e parcialmente viável). Quanto aos coordenadores, na $1^{a}$ fase $_{i} 56 \%$ dos que os conheciam, consideram-nos viáveis - parclelmento viáveis; na $2^{\mathrm{a}}$ yase, $75 \%$ 。

Dos 19 professores que conheciam os documentos, ne 1 1: 1 ase, 9 disseram que foram preparados, 4 disseram qu nå foram preparados a deixaram em branco. Dos 7 coordenadores, tambem de 1 a rase, que conheciam os novos curriculos: I disse que foi preparado, 3 disseram que na foram praparados e 3 deixaram em branco.

0 aumento dos percentuais verificado na $2^{\text {a }}$ fase pode ŝr sido devido ao curso de capacitaçäo "bem como

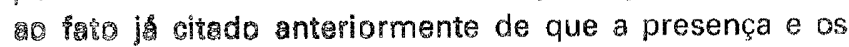
qugstonamentos feitos pelos pesquisadores poderem ter lavedo os paricipantes a procurar conhecer mais detathademente os documentos em questão.

Quando indagados sobre os ơrgäos/meios respon. ș์ curriculos, 5 professores de 19 que os conheciam e $1 \mathrm{co}$. ordenador de 5 que também os conheciam, na $1^{\text {a }}$ fase, alegaram terem sido preparados através dos cursos promovidos polo NAP/NRE/SEED em 1991 (os "cursos-re-

\section{QUADRO DEMONSTRATIVO 2 - OPINIÃO SOBRE OS NOVOS CURRÍCULOS}

I FASE

2. FASE

\begin{tabular}{|c|c|c|c|c|c|c|c|c|c|c|c|c|c|c|c|c|c|c|c|}
\hline & & V & & 1 & & PV & & $B$ & & $T$ & $V$ & & 1 & & PV & & B & & $T$ \\
\hline & $F A$ & $F \%$ & FA & $F \%$ & FA & $F \%$ & FA & $F \%$ & & FA & $F \%$ & $F A$ & $F \%$ & FA & $F \%$ & FA & $F \%$ & & \\
\hline$P$ & 08 & 31 & 0 & 0 & 08 & 42 & 03 & 16 & 19 & 10 & 53 & 0 & 0 & 7 & 37 & 2 & 10 & 19 & \\
\hline C & 02 & 28 & 0 & 0 & 02 & 28 & 03 & 44 & 07 & 03 & 75 & 0 & 0 & 0 & 0 & 1 & 25 & 04 & \\
\hline
\end{tabular}

$V=$ viåvel

$$
1 \text { = inviável }
$$

$\mathrm{PV}=$ parcialmente viåvel

$B=$ branco

Semina Ci. Soc./Hum., vo 15, n. 3, p. 205-214 
lâmpagos" já citados anteriormente). Apenas 1 professor citou a escola como responsável pela sua preparação.

$\mathrm{Na} 2^{\text {a }}$ fase, como era de se esperar, obtivemos 10 professores (de 19) que foram preparados pelos cursos de 1992, e, mesmo assim, 9 disseram que só fizeram uma leitura dos documentos. Portanto, cursos e leitura dos documentos foram os meios responsáveis pela preparação desses profissionais para a implantação dos novos currículos nas escolas participantes deste projeto.

Durante os "cursos-relâmpago" de 1991, quando tentávamos verificar, através do projeto NAP-UEL, se os novos currículos elaborados pelo governo vinham sendo implantados, constatamos, para nossa surpresa, que os mesmos não haviam sido sequer amplamente divulgados aos professores e coordenadores. Percebemos, naquele momento, que estávamos cumprindo o papel de divulgadores dos curriculos novos, para muitos em primeira mão, dal, então, o resultado acima apresentado: um aumento no número de professores que disseram "conhecer" os curriculos e estarem implantando os mesmos em suas escolas, na $2^{2}$ fase lapós o curso de capacitação/92).

Gostariamos de salientar aqui o nosso papel de "divulgadores" e "preparadores" da implantação junto aos professores participantes dos cursos dados pelo NAP em 91, quando pensávamos que estariamos desempenhando o papel de "verificadores" $e$ "avaliadores" da implantação.

Ao serem indagados, na $1^{\text {a }}$ fase, sobre como deveriam ter sido preparados, dos 4 professores e 3 coordenadores que informaram não haverem sido preparados para a implantação, 3 responderam que cursos especifi. cos deveriam ser responsáveis pelo seu preparo. Já na $2^{\text {a }}$ fase, após o Curso de Capacitação (92), um professor afirmou que gostaria de ter tido "uma preparação prática, precisa e verdadeira". Dos 2 coordenadores que acharam que deveriam ter sido preparados 1 alegou que a "preparação deveria ter sido gradativa para a equipe pedagógica e professores". O outro alegou que "de" veriam ter sido dadas explanações sobre os objetivos, conteúdos, metodologia e valorização da Lingua Inglesa nas escolas públicas".

Os dados parecem indicar que os cursos de capacitação, na área de Língua inglesa, vêm desenvolvendo um trabalho relevante no que tange à implantação de novas propostas, pois os mesmos são constantemente mencionados pelos professores e coordenadores como meios importantes de atualização e treinamento. Por conseguinte, a validade da realização periódica desses mesmos eventos ế de extrema necessidade para a melhoria de ensino nas escolas públicas.

\section{2 - DA IMPLANTAÇÃO DOS NOVOS CURRÍCULOS}

$\mathrm{Na}$ tentativa de verificar quantos professores e com ordenadores estavam colocando em prática os novos currículos, verificamos o que se segue, como demonstra o quadro 3: na $1^{\text {a }}$ fase, $58 \%$ dos professores estavam aplicando os TOTALMENTE, 31\% PARCIALMENTE apenas $10 \%$ NĀO OS IMPLANTAVAM. Já na 2a fase, $58 \%$ dos entrevistados faziam a implantação PARCLAL MENTE e $42 \%$ TOTALMENTE.

Quanto aos coordenadores, $15 \%$ na 1 a fase estavam auxiliando na implantação TOTAL e $28 \%$ na implantação PARCIAL e $42 \%$ deixaram em BRANCO. Este percentual elevado de coordenadores que deixaram em branco nos surpreendeu, pois, a nosso ver, os mesmos deveriam estar à frente do processo de implantação. $\mathrm{Na} 2^{\mathrm{a}}$ fase, $60 \%$ coordenavam uma implantação TOTAL, enquanto $40 \%$ não estavam à frente do processo de implantação. Este aumento no percentual de coordenadores, na $2^{\text {a }}$ fase, que estavam auxiliando os professores na implantação, pode ter sido fruto dos cursos de capacitação durante os quais os novos curriculos foram apresentados.

\section{A Implantaçäo total e parcial}

Os professores e coordenadores/supervisores consultados nas $1^{\mathrm{a}}$ e $2^{\mathrm{a}}$ fases da pesquisa disseram que estavam implantando os currículos totalmente ou parcialmente, porém fazendo adaptações para as suas realida. des.

Dentre as dificuldades encontradas na utilização das mesmas, algumas merecem um destaque especial. São elas:

- material didático inadequado e insuficiente

- as propostas não consideram os alunos dos cursos noturnos

- insegurança mediante uma nova abordagem

- dificuldades com a conduçäo da prática oral na sala de aula

QUADRO DEMONSTRATIVO 3 - UTILIZAÇAO DAS PROPOSTAS

1. FASE

\begin{tabular}{|c|c|c|c|c|c|c|c|c|}
\hline & & $\mathrm{P}$ & & $\mathrm{C}$ & & $P$ & & $C$ \\
\hline & FA & $\mathrm{F} \%$ & FA & $F \%$ & FA & $F \%$ & FA & $F \%$ \\
\hline $\sin$ & 11 & 58 & 01 & 15 & 08 & 42 & 03 & 60 \\
\hline NÃO & 02 & 10 & 01 & 15 & 0 & 0 & 01 & 40 \\
\hline EM PARTE & 06 & 31 & 02 & 28 & 11 & 58 & 0 & 0 \\
\hline BRANCO & 0 & 0 & 03 & 42 & 0 & 0 & 0 & 0 \\
\hline
\end{tabular}

Semina Ci. Soc/Hum., v. 15, n. 3, p. 205-214 
- dificuldade em integrar gramática ao texto

- dificuldade em seguir o planejamento sugerido nos documentos

\section{B. Näo implantação}

Os professores e coordenadores, conhecedores dos novos currículos, nas duas fases, alegaram não os estarem utilizando pelos seguintes motivos:

- falta de clareza dos documentos nas suas orientações teóricas e práticas:

- falta de preparo prévio para a implantação dos mesmos;

- falta de recursos na escla para a produção de materiais extra;

- falta de competência lingüística e metodológica;

- falta de interesse e apoio dos órgãos superiores;

- falta de assessoria por parte da coordenação e orienta ção da escola.

Além desses motivos, os participantes alegaram ainda que o numero excessivo de alunos na sala de aula, a recusa dos professores em conhecer e/ous utilizar os novos currículos e o fato de o coordenador näo ser da área, muito contribuiram para a não utilização dos documen tos.

Os participantes que responderam que estavam utilizando os novos curriculos, mas em parte, citaram que vinham fazendo adaptaçōes, utilizando jogos, diălogos e dramatização, usando os novos curriculos com o livro didático, baseando-se nos pressupostos teóricos dos documentos, encontrando, porém, dificuldades com a pråtica oral e escrita. Citaram o nümero excessivo de alunos na sala de aula como fator dificultador.

\section{3 - DA ASSESSORIA AOS PROFESSORES E COOR- DENADORES}

Esta questão teve como objetivo verificar que tipo de assessoria os participantes vinham recebendo durante o processo de implantação dos novos currículos. As respostas se encontram no quadro abaixo.

\section{OUADRO DEMONSTRATIVO TIPOS DE ASSESSORIA}

\section{TIPOS}

TOTAL

Dos colegas

Da Coordenação da escola

Do NRE-Londrina

Da SEED-PR

Outros

Dentre os outros tipos de assessoria citados pelos professores estão: cursos ministrados pelo NAP-UEL。 pelo Yazigi, pela assessoria permanente do NAP-UEL,

Semina Ci. Soc./Hum., v. 15, n. 3, p. 205-214 estágios e cursos não especificados. Troca de materiais e reuniōes também foram citados.

Nessa mesma questão, os coordenadores, quando consultados, responderam que a assessoria vinha sendo prestada através de reuniōes periódicas ou em reuniöes apenas quando solicitadas. No entanto, 7 coordenadores (de 11) não responderam a essa questão, 2 disseram que não estavam prestando assessoria nenhuma e 2 alegaram estar assessorando durante o planejamento inicial e em etapas: preparo com todas as áreas, preparo dentro da área específica e plantāo de atendimento ao professor.

Dos 36 professores que vinham implantando/utili zando os currículos nas suas salas de aula, 15 afirmaram que estavam sendo "assessoradas" pelos próprios colegas. Nosso instrumento não abrangeu a questão da assessoria em profundidade; a nosso ver essa "assessoria ${ }^{s D}$ pode ser caracterizada como uma cooperação, entre amigos, uniäo de forças, ou até um esforço conjunto para tentar viabilizar o trabalho da implantação.

\section{4 - DAS DIFICULDADES ENCONTRADAS NA UTILI. ZACAAO DOS NOVOS CURRICULOS}

QUADRO DEMONSTRATIVO 5 - DIFICULDADES COM AUTHLZACÄO DOS NOVOS CURRICULOS

DIFICULDADES

TOTAL

Em branco

$N^{\circ}$ excessivo de alunos para a pråtica oral

Falta de material didático e paradidático

Insegurança gerada pela falta de conhecimento,

orientaçăo e apoio

Carga horária insuficiente

incoerência na avaliação dos alunos

Tempo e dificuldade $\mathrm{p} /$ preparar material didático

Livro didático inadequado aos novos currículos 03

Falta de interesse dos alunos

Falta de preparação prévia para a implantação

Resistência dos professores

OBS: Esta questão era aberta.

A partir deste ponto da discussão serão considerados somente os professores e coordenadores que alegaram estarem utilizando os novos curriculos, $i_{0} e_{2}, 36$ professores (de 38 que os conheciam) e 6 coordenadores (de 11 que os conheciam).

Quanto às dificuldades que os professores e coor denadores/supervisores vinham encontrando na implantação dos novos currículos, verificamos que 18 (de 42) não responderam a essa pergunta, movidos talvez pelo fato de não estarem realmente implantando os novos currículos. Dentre as dificuldades mais citadas se encon- 
tram: número excessivo de alunos para aprática oral,faltade material didático e paradidático, insegurança gerada pela falta de conhecimento detalhado dos curriculos, e pela falta de orientação e de apoio (vide Quadro Demonstrativo 5).

Os professores foram levados, ainda nesta questão, a refletir sobre as possíveis sugestões para sanar as dificuldades acima citadas. A maioria dos participantes sugeriu cursos de reciclagem e aperfeiçoamento, cursos pelo NAP-UEL e assessorias permanentes (cooperação escola-colegas), sugerindo também turmas menores $\mathrm{e}$ maior disponibilidade de material didático e paradidático.

\section{5 - DOS RESULTADOS}

Nas $1^{\text {a }}$ e $2^{\text {a }}$ fases da pesquisa, a maioria dos participantes que vinha implantando os novos currículos avaliou o seu trabalho como bom e regular, como pode ser observado no Quadro Demonstrativo 6. As explicações dadas para tais resultados foram as que se seguem:

1. Os poucos que classificaram seu trabalho como excelente, alegaram que seus alunos conseguem se comunicar em situações reais e são bastante motivados;

2. Os participantes que afirmaram estar conseguindo bons resultados com a implantaçáo citaram que suas aulas estäo sendo mais dinâmicas e seus alunos mais motivados;

3. As explicaçōes para os resultados regulares foram diversas, tais como:

- falta de material didático

- falta de carga horária

- os alunos estão acostumados com as aulas tradicionais
- dificuldades com os alunos dos cursos noturnos

- salas numerosas

- custo alto do material extra a ser usado

Quando indagados, ainda nesta mesma questão, sobre os meios que vinham utilizando para avaliar a implantação dos novos currículos nas suas escolas, a maioria dos participantes, nas duas fases, deixou em branco, ou melhor, não respondeu, ou alegou que não vinha fazendo nenhum tipo de avaliação. Apenas alguns participantes apontaram que as avaliações vinham sendo feitas pelos próprios professores através da verificação do desempenho dos alunos (exercicios orais e escritos e autoavaliação). Por fim, citaram também que reuniões periódicas com a coordenação da escola estavam sendo feitas.

A última questão do instrumento utilizado na pesquisa tinha como objetivo solicitar dos participantes que não estavam implantando os novos currículos que fornecessem sugestóes para que tal fato viesse ocorrer em suas escolas. Na 1 a fase, a maioria dos professores afirmou que fazer um treinamento através de cursos fora do período letivo seria uma alternativa. Apenas um professor alegou que deveria conhecer bem os novos curriculos antes de usá-los. Um coordenador sugeriu encontros com professores, supervisores e coordenadores das escolas.

Já na 2- fase, as respostas foram mais variadas, como, por exemplo: deveria haver maior envolvimento dos pais no processo, mais material didático, e acompanhamento dos cursos oferecidos pela UEL pelos coordenadores e supervisores.

\section{QUADRO DENIONSTRATIVO 6 - RESULTADOS OBTIDOS COM A IMPLANTAÇĀO DOS NOVOS CURRÍCULOS}

\begin{tabular}{|c|c|c|c|c|c|c|c|}
\hline & & \multicolumn{6}{|c|}{1 a FASE } \\
\hline & & $E$ & B & $R$ & RU & $\mathrm{BR}$ & $L$ \\
\hline$P$ & & 2 & 5 & 6 & - & 3 & 1 \\
\hline C & & - & 1 & - & - & 2 & - \\
\hline \multicolumn{2}{|c|}{$E=$ excelente } & \multicolumn{2}{|c|}{$B=$ bons } & \multicolumn{3}{|c|}{$R=$ regulares } & \\
\hline \multicolumn{8}{|c|}{$\begin{array}{l}\text { QUADRO DEMONSTRATIVO } 7 \text { - PANORAMA DA } \\
\text { IMPLANTAÇĀO }\end{array}$} \\
\hline \multicolumn{3}{|c|}{ PROFESSORES } & \multicolumn{4}{|c|}{ COORDENADORES } & \\
\hline$T$ & $\mathrm{C}$ & 1 & $\mathrm{~T}$ & & & 1 & \\
\hline 53 & 38 & 36 & 15 & & & 06 & \\
\hline
\end{tabular}

$T=$ total de participantes nas duas fases

$\mathrm{C}=$ total de conhecedores dos novos currículos

$I=$ total de professores e coordenadores/supervisores que implantam os novos curriculos

2 FASE

emina Ci. Soc./Hum., v. 15, n. 3, p. 205-214 
visores que participaram desta pesquisa alegou ter tomado conhecimento da existência dos novos currículos através de cursos, da escola, dos colegas e do NRE-Londrina (no caso do coordenador), avaliando-os como viáveis e parcialmente viáveis. Os que não os conheciam manifestaram grande interesse em conhecê-los. Os coordenadores, porém, obtiveram maior indice de desinteresse, alegando estarem prestes a se aposentar. Salientamos os problemas que tais substituições podem acarretar. Com a saída destes elementos, corremos o risco de vê-los substituldos, ou por profissionais que não têm formação especifica em Língua Inglesa, e, que, portanto, não se dedicarão devidamente a essa área, ou por outros que desconhecem totalmente os novos currículos, ou, até, mesmo, por profissionais não conscientes de seu papel de elemento integrador, fomentador e verificador de quaisquer mudanças ou propostas que venham afetar o ensino.

O fato de os participantes terem "tomado conhecimento" dos novos currículos somente através dos "cursos-relâmpagos" de 1991, os quais, na época, visavam avaliar como os currículos novos vinham sendo colocados em prática, i.e., implantados, deixa evidente a falta de clareza e desorganização do processo de divulgação e implantação dos mesmos nas escolas estaduais de Londrina.

O documento do $2^{\circ}$ grau é datado de 1988 , e o do 1․ grau de 1990. Entretanto, os mesmos chegaram às nossas mãos somente em 1991. O que aconteceu durante esse hiato? Que linhas de ação o governo do Estado traçou para atingir seus objetivos em relação à divulgação, preparo prévio dos professores e implantação efetiva dos novos currículos em larga escala? Esses questionamentos, a nosso ver, mereceriam maiores esclarecimentos.

A diversidade de fontes pelas quais os participantes desta pesquisa tomaram conhecimento dos novos curriculos demonstra uma divulgação desordenada, assistemática, revelando uma atitude ingênua e de descaso pelo ensino da Língua Inglesa por parte dos órgãos superiores. Os participantes citaram a leitura dos documentos $(13 \%)$, cursos do NAP-UEL $(8 \%)$ e escola $(2 \%)$ como responsáveis pela sua preparação para a implantação dos novos currículos. Seria uma simples leitura de um documento, que objetiva mudanças de ordem filosófica, psicológica, sociológica e metodológica, suficiente para prepará-los para que tais mudanças acontecessem? Seriam os cursos do NAP-UEL suficientes para que os mesmos documentos fossem devidamente disseminados e efetivamente implantados?

Como nos diz o documento elaborado pela SEED (1992-1993):

"A teoria não é a solução para as práticas novas. Logo não basta e não se pode trocar de uma para outra. Ela está no âmago de qualquer prática. Devem as teorias iluminar, e conduzir as práticas e nestas, nelas devem encontrar explicações e fundamentação. Dal, a necessidade de atitude de constante reflexão e teorização das práticas escolares por seus alunos".

Semina Ci. Soc.JHum., v. 15, n. 3, p. 205-214
Ainda para confirmar nossa opiniäo, tomamos nossas as palavras de EISNER (1979):

"it's simplistic to assume that teachers will adopt materials that they have been inadequately exposed to and which, initially at least, make demands on them that familar materials do not."

Quanto à utilização dos novos currículos, verificamos que nas duas fases da pesquisa a metade dos participantes os utilizavam total ou parcialmente, fazendo adaptações, e, mesmo assim, encontrando dificuldades no que tange ao cumprimento dos planejamentos propostos.

Acreditamos que reestruturar significa dar nova estrutura a alguma coisa, dar nova base. Reestruturar um ensino é colocá-lo em xeque, avaliar os pressupostos que norteiam as práticas pedagógicas do momento, é provocar mudanças com vistas à melhoria, aperfeiçoamento desse ensino. Mudar, segundo FERREIRA (1987), significa dar outra direção a, não resultando necessariamente em melhoria ou aperfeiçoamento, definidos como a aquisição de maior grau de instrução ou aptidão (implicando a idéia de valorização ou aumento do nivel de excelência). Acreditamos que mudar é um processo individual, idiossincrático e endógeno, isto é, acontece (ou não) com pessoas diferentes, de maneira e em momentos diferentes, de dentro para fora, dependendo quase que exclusivamente da vontade, abertura de mente do próprio indivíduo.

Assim sendo, os cursos de capacitação podem aju dar a desencadear o processo de mudança, mas jamais poderão ser responsabilizados por ela.

Vemos na implantação dos novos curriculos, pela maneira como os mesmos foram disseminados, mais uma vez, um total descaso pelo professor e pelo processo de ensino/aprendizagem de uma lingua estrangeira em nossas escolas. A intenção do governo do Paraná de implantar novas propostas somente via cursos de capacitação é ingênua, além do que fere a autonomia das escolas.

Segundo o documento da SEED (1992-93, p. 29) uma implantação deve prever "s a participação de todos os envolvidos no e com o trabalho escolar, em igualdade, na condiçăo de parceiros interagindo desde a decisão, passando pela operacionalização até a avaliaçäo do que se propōe, realiza e aprende"t. $^{\prime \prime}$

Uma vez que os documentos visam primordialmente a mudanças com vistas a uma melhoria do nivel de excelência do ensino de Lingua Inglesa nas escolas públicas do Paraná, notamos a falta, por parte do governo, de um planejamento claro e definido, envolvendo as escolas; os NREs, e as IEs, através do qual essa implantação viria a ocorrer de maneira gradativa, parcial e com avaliações periódicas. A nosso ver, uma implantação séria, ordenada e sistemática envolveria 3 fases importantes: de planejamento, de implantação piloto, e de implantação total, como mostra o fluxograma abaixo: 


$\begin{array}{lll}\begin{array}{l}\text { Planejamento } \\ \text { total }\end{array} & \begin{array}{l}\text { Implantação } \\ \text { piloto }\end{array} & \text { Implantação }\end{array}$

Elaboração dos

Implantação em

documento com algumas escolas

a participação apenas, com:

de equipes de - apresentação

(ldem)

professores,

- discussão

coordenadores, - avaliação-Uso?

experts, etc...

Altero?
1
Uso
- assessoramento
contínuo

Duas fases importantes do processo de implantação dos novos currículos, no caso das escolas de Londrina, foram atropeladas, uma vez que, como já discutimos anteriormente, não houve envolvimento, preparo prévio dos professores, coordenadores, diretores, nem mesmo sabemos da existência de uma pilotagem desses novos currículos em escolas do Paraná.

Tomamos aqui as palavras de DOLL (1982, p. 170) ao afirmar que:

\begin{abstract}
"Whoever preplans, the cardinal rule is THINK, THINK, THINK, Thinking takes time. It's better to take a long time in the preplanning stage than to choose a design option that proves to be uninteresting or unproductive. One the major problems with designing curriculum in the past has been limiting the involvement of people who are to participate in the implementation of the program or project that is eventually chosen. Again, involving people takes time".
\end{abstract}

Este comprometimento citado pelo autor ratifica a nossa opinião de que um processo de mudança começa sempre com o desenvolvimento de um individuo que acredita nos ideais que subjazem a essa mudança, partindo para um processo de legitimação, no qual outros individuos passam a se comprometer, ocorrendo então a congruência das idéias e ideais que estão sendo propostos.

Outro problema detectado nos dados da nossa pesquisa refere-se ao tipo de assessoria que os professores vinham recebendo durante a implantação dos novos currículos. Notamos que a maioria citou estar sendo "assessorada" pelos colegas, pelos cursos do NAPUEL, pelo Yazigi, estágio e outros cursos não especificados. Acreditamos ter faltado aqui, mais uma vez, por parte do governo, um processo organizado de assessoramento constante da implantação junto aos professores. Não nos surpreendeu também o fato de os professores não estarem avaliando o seu trabalho de implantação dos novos currículos, justamente pela falta de preparo prévio. Como avaliar algo que não os envolveu desde o ińcio, não os preparou de antemão?

Semina Ci. Soc./Hum., v. 15, n. 3, p. 205-214
Os documentos em si podem estar gerando insegurança e incerteza nos professores e coordenadores, uma vez que suscitam contradições. Os mesmos foram divulgados como "propostas metodológicas", dando margem à interpretação de poderem ser seguidas ou não. Já na parte dos conteúdos, esses são tidos como "mínimos, essenciais". A coerência entre as duas partes fica comprometida, podendo ter prejudicado seu entendimento e aplicação. Outra condição pode ser percebida no Currículo Básico (ou "propostas metodológicas") (SEED, 1990) para Língua Estrangeira Moderna (10 grau, 1990), no qual as proponentes ora enfatizam o trabalho com o texto, ora a prática oral, como podemos ver através dos exemplos tirados do documento:

- "o professor poderá privilegiar o texto escrito" (p. 190)

- "TRABAlHo COM O TEXTO: Questäo DE PRIORIDADE"' (p. 191)

-..."é por isso que propomos um trabalho mais demorado com o texto em Lingua Inglesa" "( $p$. 192)

- "Essa opção pelo texto não significa que esquecemos o trabalho com a expressão oral; e justamente o contrário que nos ocorreu'". (p 203)

Na proposta do $2^{\circ}$ grau (REESTRUTURAÇÃO .... 1988), o problema parece se repetir, como podemos ver:

- "nesta proposta, o recorte de habilidade também ficou em aberto, visto que o mesmo dependerá do enfoque dado pelo professor ao trabalhar as diferentes funçōes, bem como do interesse dos próprios estudantes" (p. 9)

- "Como se trata de uma proposta para a escola secundária, a leitura SERÁ privilegiada, mas as demais habilidades lingüísticas não devem ser negligenciadas"' (p. 5-grifo nosso)

As dificuldades encontradas na interpretação dos textos tornam-se pequenas quando comparadas ao problema maior, a nosso ver, que é o da superposição de propostas para dois cursos distintos; uma parece repetição da outra. Acreditamos que o $1^{\circ}$ e o $2^{\circ}$ graus devem se integrar sim, sendo o $2^{\circ}$ uma continuidade do $1{ }^{\circ} ;$ porém, respeitadas as especificidades de cada curso.

Esta questão merece ser investigada mais profundamente em outro momento, por não ser este o objetivo deste trabalho. Temos certeza de que é na sala de aula onde realmente poderemos ter respostas a muitos dos nossos questionamentos.

Esta pesquisa é fruto de uma preocupação isolada de um projeto de pesquisa de uma universidade apenas, de uma cidade do Estado. E as demais escolas estaduais, como vêm conduzindo o seu trabalho em relação aos novos currículos?

\section{6 - SUGESTÕES}

Apesar do diagnóstico apresentado ter detectado 
falhas já discutidas anteriormente podemos vislumbrar, além das mencionadas no decorrer do trabalho, outras sugestöes para ienamos minimizarem as conseqüen. cias.

A UEL, atraves do projeto de extensäo NaP. vem assessorando, desce 1989, professores de ingless das escolas estaduais a municioais da cidade de Londrina. Essa assessoria inchi a realizaçäo de cursos de capacitaçäo. de grupos de estudos; a promoção de eventos; a oferta de um centro de recursos com marerial didático, e a recente criação do CEPLALA. Centro de Pesquisa em Lingüistica Aplicada ao Ensino de Lingua Inglesa, ao qual o pre. sente trabalho estă vinculado. O mesmo projeto tem sido solicitado por ớrgảos do govemo para ministrar a grande maioria dos cursos de capaciaçăo ate hoje oferecidos no Estado do Paraná, e com essa pesquisa procura oferecer subsídios ao plano de reestruturação/melhonia do ensino de Lingua Inglesa. Entretanto nossa relaça com o governo tem sido informal, näo reconhecida. Isto tem difi. cultado sobremaneira nossa atuaçăo Sugermos, entäo, alguns procedimentos que poderiam vir reconhecer essa integraçăo, estabelecendo algumas linhas de ação conjunta, como as que se seguem:

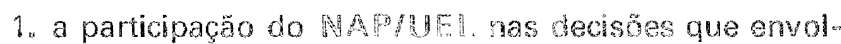
vem o ensino de Lingua inglesa;

2. a elaboraçă te um calendảno anual te cursos de capacitação on ourros avontos para que possa ser de. senvolvido um trobaho serio de aualizaço/desenvol. umento do professor, ao mesmo tempo, de asses soria continuada ao sen trabaho de implantaçäo de novos curriculos ou novas práticas pedagỏgices, que venham promover a methoria do ensino.

Concordamos com GADOTII (1992, p.39) ao afr mar:

"Chego a pergunarme ale que ponto bagho, apesar das mehores das inencoles, os chane. dos especiallias dos orgäos centrais das se crearias de educagão imporem pacotes peda gogicos e hazen experimentos pedagógicos com alunos e professores. Não seria melhor ca" da escola ter acesso a muitas propostas e conselidos curriculares, para, a partir de sua probpria realidade e experiencia, construir o projeto de escola que deseja? As reorientaçós curriculares que pantem das boas intençôes dos educa. dores situados nos gabinetes das secretarias, ate hoje, näo obtiveram, por outro lado, bons re. sultados. So obiveram bons resutados as reformas curiculares que estimularam os projetos das proprias escolas".

Levando am consideração o que GADOTT/ (1992) expóe, 0 列促 - area de Lingua Inglesa, propóe-se a desenvolver outra pesquisa com os professores e alunos das escolas públicas investigadas neste trabalho. Tomando como base os novos curriculos, tentariamos verificar. em sala de aula, como os mesmos vem sendo postos em pratica. Cremos que assim estaremos colaborando com o projero político pedagógico de cada escola, visando a in. terdisciplinaridade - tendo o inglês como um dos ale. menios integradores.

0 objetivo deste trabalho foi conseguir um diagnóstico da situação da implantação dos novos curriculos de Lingua Inglesa em 10 grandes escolas estaduais de Londrina. PR. Achamos que atravěs de entrevistas es. truturadas poderiamos consegui- 10 , assim o fizemos. No entano, sabemos de antemäo que somente entrevistas estruturadas näo nos fomecem dados reais da in. plantaça uma vez que a mesna acontece realmente dentro da sala de aula. Dal a nossa intença, num segun. do momento, de desenvolver uma pesquisa de sala de aula que nos dará essa informação.

\section{ACRAOECAMEMTOS}

Agradecemos a colaboraçäe das docentes Cleide Matatena Cordeiro Conargo, Elia Naomi Yamaue, Cisele Cilli da Cocia Ana Maria Castelo Branco Rabello, pari. cipames do Projeto NAP Lingua Inglesa, bem como dog professores e coordenadores/supervisores das ascolas envolvidas neste trabalho.

BUSNARDO, GM, T REIS, M, R.F. The New Curricula for the teaching of English in the state schools of Londrina, PR.

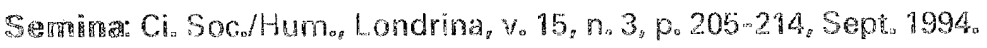

ABSTAACT: The objective of this paper is to investigate thand hom two new curricula for the teaching of English at the elementary and secondary levels are being implemented in 10 state schools of Londrina, Parank. 29 leachers and 10 coordinators/supervisors were intervjewed in the first phase of the data during collection, and 24 teachers and 15 coordinators/supervisors during the second phase. The andysis of the data shows that the implementation of the two curricula is

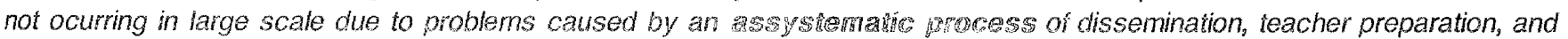
teacher involvement adopied by the State government. This study also iries to identify these problems and to suggesi means to minimize the consequences they may bring to the teaching of English in the state schools of Londrina, Parana.

KEY-WORDS: Curriculum-English Language EFL Teaching - $1^{\circ}$ e $2^{\circ}$ graus, teacher development, curriculum implementation. 
DOLL, R.C. Curriculum Improvement: Decision Making and Process. Boston: Allyn and Bacon, 1982.

EISNER, E.W. The Educational Imagination: On the Design and Evaluation of School Programs. New York: McMillan Pubiishing, $1 \hat{9} 7 \hat{9}$.

FERREIRA, A.B. Pequeno Dicionário Brasileiro de Língua Portuguesa. Rio de Janeiro: Civilização Brasileira, 1987.

GADOTTI, M. Escola Cidadã: uma aula sobre a autonomia da escola. São Paulo: Cortez, 1992.
REESTRUTURAÇÃO DO ENSINO DE 20 GRAU LÍNGUAS ESTRANGEIRAS MODERNAS. SEED-PR., 1988.

SECRETARIA DA EDUCAÇÃO DO ESTADO DO PARANÁ. Consiruindo a Escola Cldádã. Curitiba, 1992-1993.

SECRETARIA DA EDUCACÃO DO ESTADO DO PARANÁ. Curriculo Bâsico para a Escola Pública do Estado do Paraná. Curitiba, 1990.

Recebido para publicação em 4/4/1994

\title{
SISTEMA JURIDICO DO SHOPPING CENTER
}

\author{
JUSSARA SUZI ASSIS BORGES NASSER FERREIRA ${ }^{1}$
}

FERREIRA, J.S.A.B.N. Sistema juridico do shopping center, Semina: Ci. Soc./Hum, Londrina, v. 15, n. 3, p. 214-217, set. 1994 .

RESUMO: O sistema juridico do shopping center apresenta gama considerável de peculiariedades, em parte, decorrentes da ordem normativa maior, como ainda resultantes da auto-regulamentação. As conseqüências jurídicas analisadas são complexas; necessitando normatização mais equitativa.

PALAVRAS-CHAVE: Shopping Center - Sistema Juridico, Shopping Center - Auto-regulamentação

Etimologicamente, sistema vem do grego Systema - Sym - istemi, ou seja, aquilo que 2 composto ou construido.

Atualmente, após sucessivas etapas conceituais, o termo sistema, em direito, passa a compreender o conjunto de normas vigentes a princlpios, logicamente ordenados e coesos, com intenção de descrever, explicar ou dirigir o funcionamento de um todo, vale dizer, o universo juridico.

Nesse sentido, o sistema jurídico, como outros sis. temas, visa objetivar regras para viabilizar a composição funcional do universo que the é próprio. Entretanto, o sistema juridico näo se subsume à mera composição orgânica, não é apenas o "construldo". Despido de hermetismo, sensivel a realidade social, não resta encerrado em si mesmo. Sem pretender ser definitivo, não impor for mas estáticas, busca facilitar que, da dinâmica dos fatos econômicos e sociais, emerjam formas juridicas que permitam a conexäo de realidades distintas, com as mais variadas espécies de normas vigentes. $E$, é, exatamente, neste ponto, que reside uma das finalidades principais do direito.

Explica MARIA HELENA DINIZ que

"o agrupamento sistemático de normas é tarefa básica do jurista, pois para compreender juridim camente um problema deve buscar normas de diversos ramos do direito. Por isso a sistematizaçẫo liga-se as fontes do direito. O sistema jurfdico é um sistema diferenciado e autônomo, pois controla o que deve ou não ser juridicizado, ou seja, o que é juridico e o que não é, isto é, regula o que deve entrar e o que deve sair". (DINIZ. 1992, p. 185)

1 - Departamento de Direito Público/CESA - Universidade Estadual de Londrina, Caixa Postal 6001, Londrina, Paraná, Brasil, CEP 86051-970. 